\title{
CONDITIONS AND PERSPECTIVES FOR DEVELOPMENT OF THE TOURISM IN DOJRAN AS WELL AS DOJRAN LAKE
}

PhD. Zlatko Jakovlev University Goce Delcev 2000 Stip, Republic of Macedonia MSc. Blagica Arnaudova University Goce Delcev 2000 Stip, Republic of Macedonia, Faculty of tourism and business logistic Gevgelija Mob.phone: 0038971251254 e-mail: arnaudovablagica@yahoo.com

PhD. Cane Kotesk and University Goce Delcev 2000 Stip, Republic of Macedonia PhD. Nikola Dimitrov University Goce Delcev 2000 Stip, Republic of Macedonia

\begin{abstract}
The favorable location, climate as well as the natural resources are the basic conditions for tourism development in one area.
\end{abstract}

The wealth from the historical past, with visible marks in the present, the cherishing of the tradition and the culture and also the imperative for modernization of the basic and the unnecessary, complement the natural resources and lead to huge potential for tourism development.

Taking into consideration the profit, it is unquestionable that it is realized through tourism, consequently to this, better tourism leads to better income.

From the above mentioned, in this master paper we will describe Dojran and Dojran Lake, as well as the possibilities for development and the affirmation of the tourist potential of this area. Through the conditions that are present, perspectives and the appetites for the increasing of the attraction, we will present this Macedonian pearl that is located in the south-east part of Republic of Macedonia as a tourist destination that is worth visiting.

Key words: perspectives, development, tourism, conditions

\section{Introductions}

Located in the south-east part of Republic of Macedonia, on the very border with Republic of Greece, Dojran and Dojran Lake are tourist destinations which are easily available for everyone.

The favorable climate throughout all the year, especially the extended summer tourist season offers possibility for extended accommodation and maximum usage of the tourist facilities. The catering and hotel facilities, casinos and restaurants are available for the visitors during the peak of the season and during all the year.

The area of Dojran and the surrounding is rich with natural beauties and resources, tourist attractions, cultural- historical monuments and landmarks.

In last years, Dojran offered great number of activities in the area of development of the culture and tradition, organizing plenty of manifestations in the area of culture, art, music, cookery and sport.

Representing the authenticity of this region, and the organization of musical and cultural events with local artists and artists from abroad, this town has a tendency to gradually return the attractiveness of the local people and the foreigners.

The investment in order to improve the conditions, from point of view of using the lake by constructing and renovation of the sandy beaches, sports fields, paths for walking, are part of the activities that contributed Dojran to be back in the map of tourist destinations.

The increasing of the natural beauties affirmation and resources, as well as the healing capacity of the lake water and the mud in the lake, the idea for reestablishment of the traditional way of fishing using the so called method of fishing using dairies, would place Dojran in higher level in the list of worth visiting places. 


\section{Conditions for development of the tourism in Dojran}

Combination of the natural-geographic, anthropogenic and material conditions are the foundation for rich tourist offer and development of the tourism in a specific region.

The favorable geographic location and the developed road infrastructure make Dojran easily accessible tourist destination. Located in the south-east part of Republic of Macedonia, beside the MacedonianGreek boarder, Dojran in the meantime represents a transit territory.

${ }^{1}$ In general, the climate is under Mediterranean influence and it is characterized by hot and dry summers with high temperatures, and mild and wet winters. This climate has a favorable affect on the tourist season, which owing to the climate, lasts longer and it leads to extended usage of the tourist facilities. Owing to the mild winters, Dojran is an excellent place to be visited, it is wonderful place for vacation and recreation throughout all the year.

The biggest water resource and the basic engine of all the activities in the municipality is Dojran Lake.

${ }^{2}$ The biggest significance for the tourist development is the average temperature of the water in the summer time of the year. The temperature is higher than 18 degrees Celsius five months in a year. That means that in time period of half an year there are thermal conditions for tourist activities such as the swimming.

Being the smallest and the warmest natural lake, Dojran Lake offers sandy beaches, exposed to sun during all the day from the

\footnotetext{
${ }^{1}$ http://www.dojran-info.com/

${ }^{2}$ PhD. Naume Marinoski (2006) „Hydrographic and hydrologic tourism values" in Tourism geography Faculty of Tourism and Management - Ohrid, pp. $211-217$
}

morning hours until dark, which means that the favorable conditions for tourism are increasing. The beaches by the lake, in last years, are full of tourists who more often choose Dojran as a destination for their holiday due to the increased water level of the lake and the organization of the beaches and the lake shore.

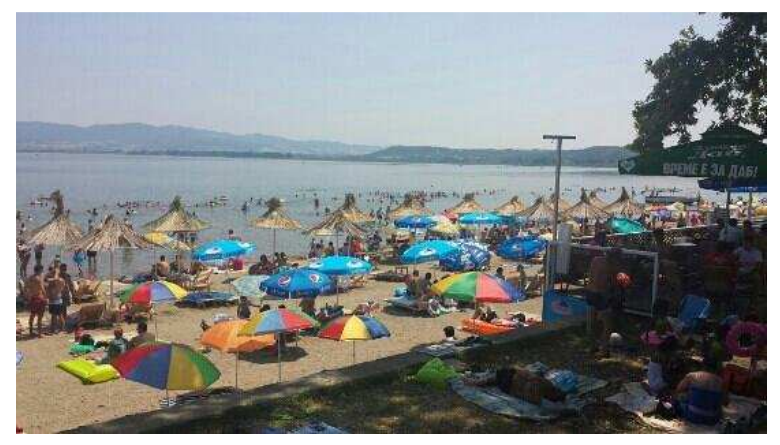

Figure 1. Beach of Lake Dojran

The wealth of the lake water is added by the algae and the mud which through its healing capacity increases the tourist offer also in the area of the health tourism.

The water from Dojran lake is enchanting and miraculous. When you enter into the lake, you can feel the mud beneath your feet and you can breathe the smell of the algae. The blooming of the algae in the lake is caused by the foam which means that it is completely natural. This happens only 15 days in the year and at that time, the water is the most healing. Owing to the combination of the lake algae, the mud as well as the Mediterranean climate, Dojran is recommended to be an ideal place for rehabilitation for people who suffer from sicknesses of respiratory organs, rheumatism and sciatica and also for healing wounds. The mud is very rich with minerals which pleasantly affect on the skin and on the rheumatic diseases. ${ }^{3}$ The local residents believe that, many centuries ago, the great military commander Alexander III Macedonian, took his military in Dojran to

\footnotetext{
3 http://babinlek.com/mokta-na-lekovitata-kal-vodojranskoto-ezero/
} 
have a bath, to relax and to heal using the mud.

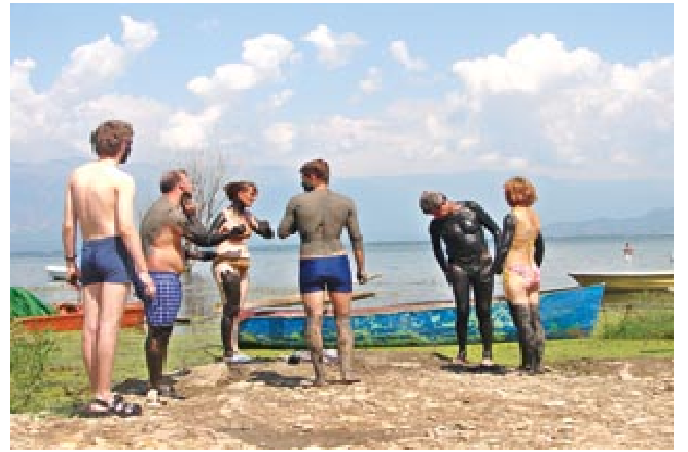

Figure 2. Spread with mud in Dojran Lake

The fishing tourism is an important part of the tourist offer in Dojran. The big quantity of fish, the way of fishing and the way of fish preparation give a great possibility to develop the fishing tourism. The fishing in Dojran lake, has always been the main economic activity for the local residents. In the past, in the world scientific literature, the lake had been presented as one of the most productive lakes in Europe.

Beside the regular fishing, Dojran Lake is also well-known for its unique way of fishing.

Since ancient times, the local residents used the reed on different ways, including the fishing. The big quantity of reeds was used to make special kinds of traps for catching fish, they used the reed in different shapes, designs and size (dairy, chop or pond).Also, the fisher men were fishing using water birds, they cut off the primary leathers of the birds and kept them close to the dairies. These birds are actually used as hunters of fish in the fishing traps. This kind of old fishing technique is very efficient, because only from one dairy on this way, 20,000 to 30,000 kilos of fish may be caught. Fishing helped by dairy is the most attractive fishing of all kinds in the Dojran Lake ,but in the meantime, it is the hardest and the longest period of fishing, which in the last 20 years is not used anymore because of the water withdrawal. This is the nowadays reality, weather it is going to be like that in future, time will tell.

Dojran town disposes with a rich offer of preparation, cooking and serving of the fish. Since ancient times, people in this region considered the fish to be the main and delicious course, so they cooked it in different manners which are even used nowadays.

Some of the most characteristic Dojran fish dishes are: fish stew, spawn stew, carp chop, fish prepared on reeds, fish in frying pan, baked carp, carp prepared in pot, vegetable stew of carp etc.

The natural resources and the geographic location made Dojran to be intersection for centuries, habitation as well as residence for the Macedonian people but also for the people who enslaved Dojran for several times.

Dojran had been built and destroyed, fired and then renewed, there are visible marks from the turbulent past in this town and in the surrounding with plenty of buildings from different cultures and people.

Some buildings from the ancient past and recent past but with very significant meaning are the several churches, fountains, baths, the Clock Tower, monuments, schools and museums

\section{Perspectives for tourism development in Dojran town and Lake Dojran}

Symbiosis of natural conditions and resources, from one side, as well as the ambitions and the commitment of the society, from the other side, are actually the key for progress and development of one region. From this point of view, Dojran along with the Dojran Lake represent natural resource with favorable natural conditions and also with remarkable activities in the area of the social development and increasing of the tourism level and the tourist consciousness. 
The cultural events and the manifestations make people get closer and it helps people to overcome the differences, and Dojran is a municipality that organizes and proves that there is a will to spread and implement cultural events, to revive and continue the existing ones. Lately, Dojran turns into highly cultural and tourist centre on the Balkans, with numerous manifestations that are being organized throughout all the year on a very high level. Some of the most well known manifestation that take place in Dojran are : "Dojran Gourmet Fest", “ Promotion of wild fig jam", "Baskerfest", “ D Festival”, “ Dojran authentic”, " Trades people Fair", "Skilful Woman” etc.

By maintaining these types of manifestations, from local and international point of view, the possibilities for affirmation, meeting and increasing of the interest for visiting Dojran and Dojran Lake are boosting.

Very big perspective for Dojran represents the Announcement for Dojran to be the Town of Culture for the year 2016 which will contribute to enhance the culture in this region as well as for its affirmation and development.

The successful long lasting period of filling Dojran Lake with water, as well as this year's natural increase of the water level, may lead to organization of sports manifestations which will make Dojran more popular and will increase the interest for Dojran Lake. There has been several years organization of races in the Macedonian Cup for remote swimming with tendency to achieve higher international rating.

The increasing of the water level, consequently led to increasing of the fishing fund as well as returning of the idea to implement the traditional way of fishing. Through the investment of this nearly forgotten technique for fishing, it is insisted to return this old tradition and also to increase the interest to visit this town, by showing the people this technique visually.

From point of view of the perspective and the enhancing of the tourism, Dojran Municipality has a plan for many projects such as : "Spa hotels with golf courses", " Hotels with sports fields", "City built above the water", "Rail rope on water", “ Construction of wineries" and many other projects. Special advantage for the possible investors is the sale of the construction area which is in state property with starting price of 1 euro per square meter.

The positive effect of the undertaken measures in order to improve the conditions and the perspectives for development is about to come. The future commitments and the time shall show i.e prove and shall maintain the desired result.

\section{Conclusion}

The variety of the natural resources, cultural and historical monuments as well as the tradition are the potential conditions for tourism development in one region.

To make a tourist attraction by using what the nature offers, using the past remains and the possibilities of the future is actually an ambition that every society is heading to.

The combination of activities in different areas, promote one region as a complex tourist location. Dojran and Dojran Lake are actually the place where the culture, history, tradition and most of all the nature intersect in one homogeneous unit.

Dojran Lake offers sandy beaches, warm and healing water, healing mud and rich fishing fund. The organization of sports activities on the lake, and out of it, actually complements the tourist offer. The manifestations that take place throughout all the summer and year, attract and keep the tourists. 
Thanks to the increasing water level, the number of tourists is increasing and it also leads to investments such as construction of facilities for accommodation, vacation and relaxation.

The ambitions for tourism development in Dojran do not cease, there are new ideas and projects which foresee Dojran as a modern tourist center with great combination of the rich past and tradition.

For sure, Dojran and Dojran Lake are slowly taking their place back in the map of tourist destinations that are worth visiting.

\section{References}

Phd. Jakovlev, Z. (2009), Free time and alternative tourism,pp.19.
PhD. Marinoski, N. (2006) „Hydrographic and hydrologic tourism values“ in Tourism geography Faculty of Tourism and Management - Ohrid, pp. $211-217$.

(13.07.2013) „The power of healing mud in Dojran Lake" - alternative medicine, posted on in journal Babin Lek, http://babinlek.com/.

(Jan 31, 2014) Dojran investment possibilities video made by Total Media Production, http://www.total-media.ch/

Official website of the Municipality of Dojran, Geographical description and population http://www.dojran-info.com/.

Association of Macedonians in the Republic of Croatia, Dojran - natural monument, http://www.zmurh.hr/2012/04/08/dojransko-jezerospomenik-prirode/. 